Perspective

\title{
Environmentally Persistent Free Radicals as Sources of POPs
}

Eric P. Vejerano ${ }^{1,}{ }^{*}$, Jeonghyeon Ahn ${ }^{1}$, Junaid Latif ${ }^{2}$, Mustafa Mamun ${ }^{1}$

1. Center for Environmental Nanoscience and Risk, Department of Environmental Health Sciences, 29208, University of South Carolina, Columbia, U.S.; E-Mails: vejerano@mailbox.sc.edu; ja22@email.sc.edu; msmustafa@email.sc.edu

2. College of Natural Resources and Environment, Northwest Agricultural and Forestry University, Yangling, China; E-Mail: junaid1990@nwafu.edu.cn

* Correspondence: Eric P. Vejerano; E-Mail: vejerano@mailbox.sc.edu

Academic Editor: Zed Rengel

Special Issue: Persistent Organic Pollutants

Adv Environ Eng Res

2021, volume 2, issue 2

doi:10.21926/aeer.2102010
Received: January 17, 2021

Accepted: May 09, 2021

Published: May 13, 2021

\begin{abstract}
Environmentally persistent free radicals (EPFRs) are a new class organic pollutant sharing some of the attributes of persistent organic pollutants (POPs). This opinion/short review aims to describe the properties of EPFRs that merit their recognition as an additional and potentially significant source of POPs. EPFRs are ubiquitous in diverse environments because of multiple factors: (1) organic precursors from anthropogenic, biogenic, and other natural emission sources are abundant; multiple mechanisms in PM and soils form (2) EPFRs; and (3) EPFRs are stable and persist for a long time, thereby, accumulate in the environment and potentially transported long range. The hazards of EPFRs arise from their ability to induce oxidative stress and the formation of hazardous byproducts. EPFRs are ultimately deactivated by reactive processes, yielding molecular recombination byproducts that are structurally similar to those classified as POPs. It is plausible that EPFRs may form POPs in vivo in organisms; therefore, they are potential additional sources of exogenous POPs. Understanding the formation of EPFRs and extensive investigation of the pollutants
\end{abstract}

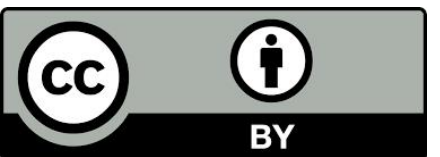

(C) 2021 by the author. This is an open access article distributed under the conditions of the Creative Commons by Attribution License, which permits unrestricted use, distribution, and reproduction in any medium or format, provided the original work is correctly cited. 
generated from their recombination will add to the growing body of knowledge on their environmental and health hazards.

\section{Keywords}

EPFRs; POPs; free radicals; dioxins; furans; persistence

\section{Introduction}

Main text Research on environmental contaminants released from diverse sources has focused primarily on organic molecular pollutants, such as persistent organic pollutants (POPs). POPs are anthropogenic chemicals that persist in the environment, bioaccumulate through the food web, and pose a risk to human health and the environment. Recently, there is a growing interest in understanding molecular mechanistic processes in investigating environmental contaminants as deemed from the increasing number of papers published since 2008 from various researchers globally. One such class of pollutants is environmentally persistent free radicals (EPFRs). Over the last decade, research on this new class of pollutants has contributed to our knowledge that environmental contaminants can exist as long-lived free radicals [1-3]. EPFRs have received more attention in the last decades because of their ability to induce oxidative stress that leads to multiple health dysfunctions [4, 5]. EPFRs are well known to produce reactive oxygen species [6, 7]. A single EPFR can generate 10 hydroxyl radicals [8]; given the ability of EPFRs to cycle catalytically, renders them more hazardous than conventional environmental pollutants.

In this paper, we describe the properties of EPFRs that merit their recognition as an important contributor to POPs. We describe the ubiquity of EPFRs in the environment because of factors responsible for their formation, stability, and persistence. Figure 1 summarizes the emission sources and processes that have been known to contribute to the formation of EPFRs and the processes that convert them to POPs in different environmental compartments. 


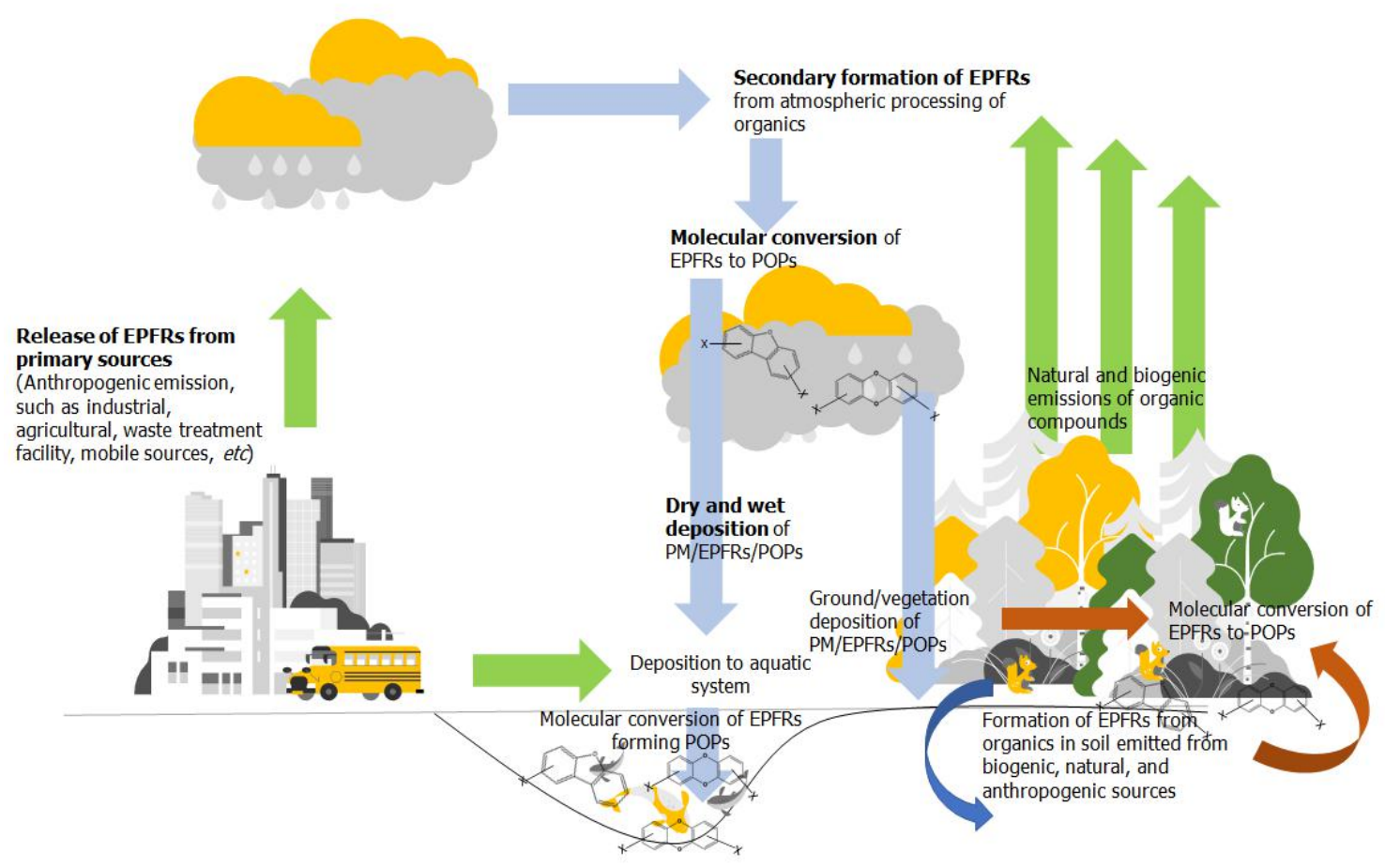

Figure 1 Formation of EPFRs from various environmental matrices and their ultimate conversion to persistent organic pollutants (POPs). Secondary processes such as oxidation and multi-generational processing of VOCs can produce EPFRs. Degradation, conversion, and transformation of organic matter in soil produce EPFRs that will eventually recombine to form POPs. Wet and dry deposition of EPFRs in aquatic surfaces can facilitate the formation of POPs (e.g., polychlorinated dibenzo-p-dioxins and furans). The persistence of EPFRs depends on the matrices, but EPFRs are extremely long lived compared to other free radicals (i.e., atmospheric free radicals). A common pathway for many of these processes is the formation of EPFRs by transition metals as that are abundant in PM and in soils. These multiple sources, the abundance of precursors, and diverse pathways demonstrate the accumulation of EPFRs in the environment.

\section{What are EPFRs?}

Free radicals are unstable species or atoms carrying unpaired electrons. Conventional, small inorganic free radicals are highly reactive, transformed into molecular species within a fraction of a second. EPFRs (e.g., cyclopentadienyl, phenoxyl, and semiquinone radicals), when constrained on surfaces, are long-lived existing for at least several minutes [1]. Persistent free radicals were first identified in the 1950s when Ingram and colleagues detected paramagnetic signals in carbonized coal and charcoals [9]. But only in the nearly two decades, the presence in environmental matrices and health significance of EPFRs have been extensively studied [10]. In earlier studies, EPFRs are known to form during incineration and thermal processing of organic wastes [1]; hence, EPFRs were first detected in combustion sources, e.g., particulate matter (PM) and fly ash $[1,11,12]$. 
Dellinger and colleagues defined EPFRs as stable free radicals, meaning they do not degrade after being formed and exhibit lifetimes sufficient to cause exposure and exert adverse health effects [1]. EPFRs are observable under the standard conditions for measuring paramagnetic species using a continuous-wave electron paramagnetic resonance spectrometer. Historically, the first attribution of the term EPFRs was to the free radicals generated from hydroquinone on copper oxide surface, which has a natural lifetime of 27 mins [1]. Since then, the term "EPFRs" has been used to describe persistent free radicals in diverse environments.

\section{Mechanisms of EPFR Formation}

The early hypothesis on EPFR formation mechanism has been assumed to be catalyzed by redox-active metals only [10]. As research on EPFRs progressed, EPFRs are known to form via multiple pathways and have been detected in other environmental matrices such as soils [13, 14]. Transition metal oxide nanoparticles/surfaces and aromatic organic species are the key components that produce EPFRs. In earlier studies, EPFRs are known to form when a resonancestabilized molecule interacts with a transition metal oxide surface at temperatures $<400{ }^{\circ} \mathrm{C}$ [1]. The current model involves three steps [1, 15]. First, an aromatic organic molecule (e.g., substituted benzene) physically sorbs on a metal oxide surface. Second, a substituent is eliminated from the aromatic precursor forming a chemically bonded species on the metal surface. Third, an electron reduces the metal center (i.e., $\mathrm{Cu}^{2+}$ to $\left.\mathrm{Cu}^{+}\right)[1,16]$ forming an EPFR. The surfaceassociated EPFR isomerizes, resulting in highly stable oxygen- and/or carbon-centered radicals [1, 15]. In laboratory studies, EPFRs form on various transition metal oxide nanoparticles: CuO [1], $\mathrm{ZnO}$ [2], $\mathrm{NiO}$ [17], $\mathrm{TiO}_{2}$ [18], $\mathrm{Fe}_{2} \mathrm{O}_{3}$ [19]. Organic components in soil matrix demonstrate that soil organic matter (SOM) produce organic radicals $[13,20]$. Hence, there is a growing trend in studying EPFR formation in soils as deemed from the increasing number of papers published on this topic since 2008.

Regardless of the matrix, a common feature of these mechanisms is the formation of EPFRs via a metal-assisted pathway. In large macromolecules such as biochars, oxygen-functional groups interact with metals forming EPFRs, although EPFRs have been reported to form in the absence of metals [21, 22]. EPFRs also proceed via band bending [18, 23], which may be the mechanism for those forming on unsupported metallic or non-metallic nanoparticles (no Schottky contact). Another pathway for EPFR formation is that some soil components mediate electron transfer from organic precursors (e.g., humic substances) to transition metal centers in clay minerals [24-26].

Another route for EPFR formation is homolytic cleavage of weak chemical bonds such as the C$\mathrm{O}, \mathrm{C}-\mathrm{C}$ bonds in $\alpha$ - and $\mathrm{B}$-alkyl aryl ether bonds [21, 22]. This mechanism is responsible for the high EPFR yields in biochars [21, 22].

\section{Lifetimes and Factors Affecting the Stability and Persistence of EPFRs}

Perhaps, the most important attribute that EPFRs share with POPs is their long lifetimes. Their persistence is unequaled by other known radical species in the environment; EPFRs persist for several minutes to months [1, 27-31]. Figure 2 compares the lifetimes associated with different free radicals to that of EPFRs. Their extreme persistence allows them to be transported over considerable distances such as those during the Asian dust storm in 2016 [32], where they can exert their adverse effects. The stability and persistence of EPFRs depends on the type of metals 
[2]. Overall, in PM and soils, EPFRs decay slowly, accumulating in significant quantities ranging from $10^{16}-10^{19}$ spins/g of PM or soils [13, 22, 33-35].

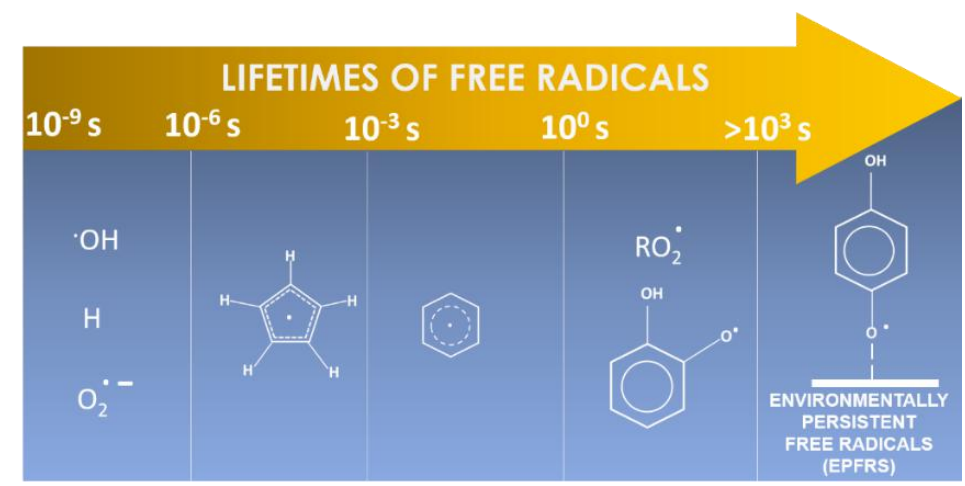

Figure 2 Lifetimes of different radicals. EPFRs have lifetimes ranging from several minutes to months. EPFRs' long lifetimes result from the surface-confinement of the unpaired electron.

The stability of EPFRs on surfaces has been attributed to several mechanisms: hyperconjugation [12, 36], steric effects [37], inductive effects of electronic repletion [38, 39], hydrophobic associations, and $\pi$-stacking interactions [13]. The concentration and persistence of EPFRs are affected by multiple factors, primarily by molecular oxygen, relative humidity (RH), and $\mathrm{pH}$. Reaction with molecular oxygen is the primary sink for the deactivation of EPFRs to molecular species [2]. The presence of water deactivates EPFR; EPFR concentration decreases $5 \times$ faster at an $\mathrm{RH}$ of $\sim 75 \%$ than those exposed to less humid conditions $[28,30]$. pH affects EPFR stability by shifting the type of EPFRs such as those in cigarette smoke [40]. Differences in $\mathrm{pH}$ affect the availability of transition metals due to redox reaction, autooxidation, and complexation [41, 42]. Overall, the accumulation of EPFRs in these matrices is because the unpaired electrons are confined on a surface, which considerably slowed down the processes that deactivate them.

\section{Sources and Precursors of EPFRs}

Many organic molecules are EPFR precursors. These classes of organic compounds have been reported to form EPFRs: aromatics [40, 43, 44] chloroaromatics [2, 45-48], polycyclic aromatic hydrocarbons (PAHs) [49, 50], complex organic polymers [31, 51], and microplastics [52]. Another abundant source of EPFR precursors is soil, which contains a vast reservoir of metals and organics [20]. There are many classes of EPFR organic precursors in soils. The yields and stability of EPFRs produced in the matrix of the organic materials are highly dependent on the complex structure of organic compounds. Processes in soils can convert or degrade large macromolecules to form similar molecular structures to known EPFR precursors. Humic substances in soils are composed of weakly associated molecular assemblies of heterogeneous polymer-like structural parts [53, 54]. Lignocelluloses are the parent compounds of biochar and the main precursors of EPFRs in soils [55, 56]. Partial decomposition of these materials produces phenol, catechol, and hydroquinone, which are established EPFR precursors [22]. Sewage sludge offers abundant biomass containing high concentrations of organic compounds [57]. 


\section{EPFRs Accumulate in Diverse Environmental Matrices}

Based on the above discussion, EPFRs are prevalent in the environment for three reasons. First, EPFR precursors emitted from anthropogenic, biogenic, and other natural emission sources are abundant in multiple environmental compartments. Additionally, environmental organic contaminants can be converted to EPFR precursors by secondary processes. Second, EPFRs are formed by multiple mechanisms in the presence or absence of metals. For metal-assisted formation, metals are abundant in PM and soils. Third, EPFRs are stable and persist for a long time, enhancing their potential for long-range transport.

PM and soils are two of the major environmental matrices in which EPFRs have been well known to form. In PM, the concentration of EPFRs formed over different transition metals is two orders of magnitude higher [33-35] than those on soils [13-22]. EPFRs in PM predominantly originate from combustion sources. However, laboratory studies have demonstrated that some volatile organic compounds (VOCs), e.g., isoprene and naphthalene, when converted to secondary atmospheric aerosol (SOA), form EPFRs [7]. EPFRs in soils and sediments are mainly produced by secondary processes. Moreover, those in sediments and soils are formed at relatively lower temperatures and even at ambient conditions [13, 14, 21, 58, 59].

EPFRs have been detected in combustion systems [60], coal and wood-burning sites [13], residues produced by burning various plastics [11, 52], municipal and solid waste incineration [61], contaminated soils $[28,62]$, pyrolysis of biodiesel and biochars $[63,64]$, soils from Superfund wood treating sites [14, 62], decomposition of microplastics [3, 53], and fly ash produced by municipal waste incineration $[61,65,66]$. Extremely long-lived asphaltene - and semiquinone-type radicals have been detected in tar-balls collected from the Gulf of Mexico after an oil spill [67]. Thermal degradation of fossil fuels and biodiesels produces carbon-centered aromatic radicals [63], and so are bituminous coal [13]. During hydrochar processing and thermal carbonization of sewage sludge, EPFR can form even at relatively low temperatures of $120-280{ }^{\circ} \mathrm{C}$ [57]. Biochar produces oxygen- and carbon-centered EFPRs $[64,68]$ even in the absence of transitions metals with yields as high as $10^{18}$ spins/g [21].

Emerging pollutant such engineered nanoparticles (ENPs) is another contributing factor for the formation of EPFRs [69]. Majority of ENPs produced are metallic [70]. Although only a small fraction of ENPs will enter the atmosphere [71], emissions of pollutants catalyzed by ENPs such as EPFRs [10] and eventually POPs are reasons for concerns. Most of these ENPs will end up in landfills (>95\%) $[69,71]$; in the presence of an abundant organic waste may easily form EPFRs. In an earlier paper, we hypothesize that because the band gap for nanoparticles exhibits sizedependence, thermally excited electrons can cross this band gap easily [72]. Some ENMs, depending on size, electronic, and chemical properties may form and stabilize aromatic species to form EPFRs [73]. ENMs can serve as charge carriers and transport electrons and holes with a high probability and efficiency [72]. This phenomenon is similar to the electron shuttling capabilities of some soil components responsible for producing EPFRs. Non-metallic ENMs can form EPFRs as long as they survive incineration and exit into the post-combustion zone intact [69].

\section{EPFRs will Recombine to Form POPs}


Although relatively highly stable and persistent, oxygen- and carbon-centered EPFRs will ultimately recombine to form molecular byproducts, including those classified as POPs. Among the POPs identified by the Stockholm Convention are pentachlorobenzene, hexachlorobenzene, pentachlorophenol, polychlorinated naphthalenes, polychlorinated biphenyls (PCBs), tetrabromodiphenyl ether, hexabromodiphenyl ether, pentabromodiphenyl ether, decabromodiphenyl ether, polychlorinated dibenzo-p-dioxins (PCDDs), and polychlorinated dibenzofurans (PCDFs). Most of these POPs can be classified into these three classes: 1) halogenated aromatics (substituted benzene and naphthalenes), 2) halogenated biphenyl ethers, and 3) PCDD/Fs. These classes have been observed as recombination byproducts of EPFRs in liquid media $[1,73]$.

EPFRs easily recombine when in liquid media because of the lower activation energy [48]. The most notable of the POPs from EPFRs are PCDD/Fs. Scheme $1 \mathrm{~A}$ and $1 \mathrm{~B}$ depict the general pathway for the formation of PCDD/Fs from EPFRs [74]. Accumulation of PCDFs is more likely to dominate as they are formed from two surface-species compared to PCDDs that require another gas-phase species [75]. EPFRs, when converted to molecular species, are capable of being halogenated [48]. Of course, the simplest molecular byproduct of an EPFR is its reconversion to its parent molecules. Pentachlorophenoxyl EPFRs have been detected in soils obtained from a Superfund site [12]. Upon extraction, the EPFRs are converted back to pentachlorophenol. Condensation of phenoxyl radicals will form cyclopentadienyl radicals [76], which upon recombination will produce naphthalene [76]. Whereas recombination of chloro/phenoxyl EPFRs will form diphenyl ethers [48, 74]. Scheme 2 depicts the formation of 2,3'-dichloro-2'-hydroxydiphenyl ether [73].
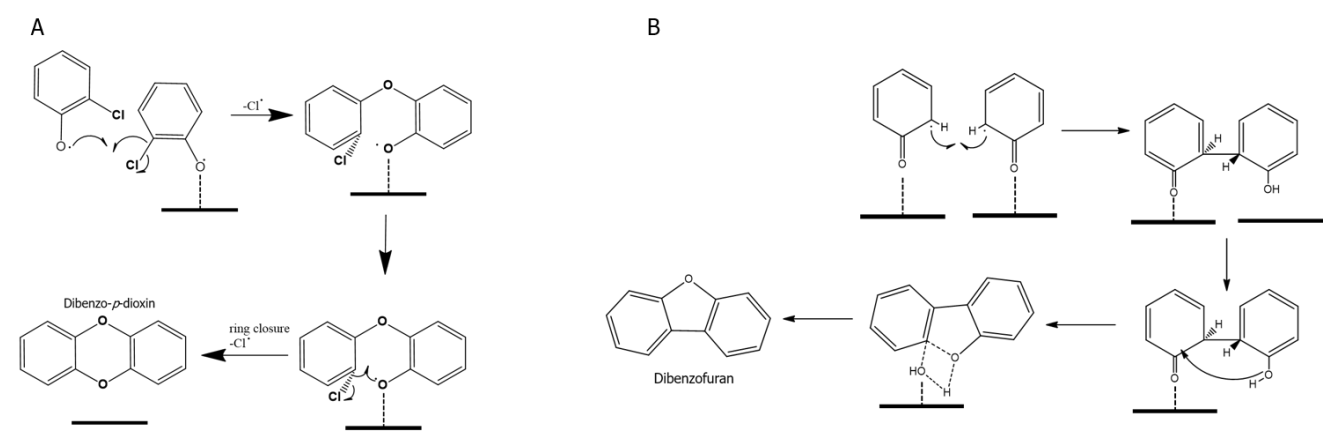

Scheme 1 (A) Formation of dibenzo-p-dioxin from reaction of 2-monochlorophenol and chlorophenoxyl radical, and (B) dibenzofuran from recombination of two keto forms of phenoxyl radical. For simplicity, the halogens were omitted. Black bar represents the surface. Adapted and simplified from the mechanism proposed by Lomnicki and Dellinger [74]. 


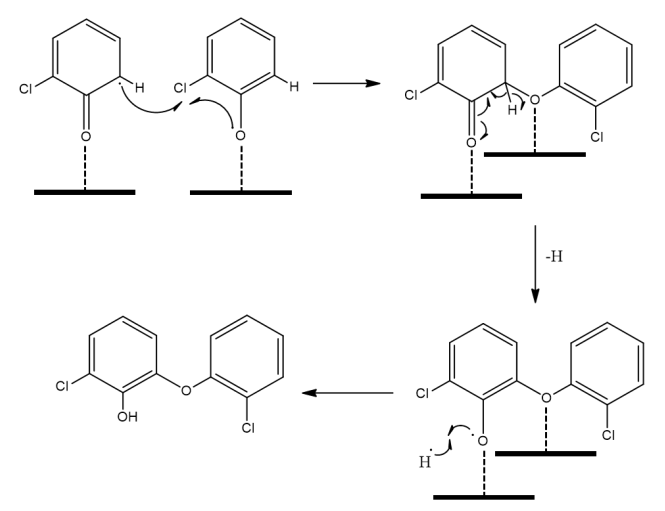

Scheme 2 Formation of 2,3'-dichloro-2'-hydroxydiphenyl ether from two chlorophenoxyl radicals [73]. Black bar represents the surface.

Mechanistically, the POPs listed above can form easily; their formation is subject only to the presence of precursors with the correct substituents. Given these possible mechanisms for POPs, inhalation of PM and soil particles will convert EPFRs to POPs. EPFRs extracted with protic organic solvents (those with donatable hydrogen) formed byproducts that are classified as POPs [48]. Since water is a protic solvent; it is plausible that EPFR-containing PM may form POPs in biological systems in vivo. Hence, this pathway may be an important exposure to POPs in humans, aside from exogenous sources.

EPFRs are non-volatile compounds because they are bound onto nanoparticle surfaces. Events such as the Asian dust storm of 2016 will transport EPFR-containing PM and/or soil particles, which have been shown to promote oxidative stress [32].

\section{Summary and Future Research Direction}

Studies on environmental pollutants have focused heavily on primary emission of organic pollutants. What is lacking a more thorough understanding of mechanistic processes that eventually produce pollutants from primary emission sources. Pollutants like EPFRs are ubiquitous in the environment, not only from direct emission from primary sources but from secondary processes in diverse environments. EPFRs are stable, persistent, prevalent in the environment, and exhibit characteristics that distinguish them from other conventional pollutants. However, EPFRs share some properties attributed to POPs, more importantly, their persistence. Unlike POPs, the hazards from EPFRs are two-fold. First, EPFRs are capable of redox cycling in biological systems, inducing adverse health effects. Second, when EPFRs ultimately recombine or deactivated by reactive processes, some of the molecular byproducts formed are hazardous POPs. These processes are additional sources of POPs.

The almost two decades of studies devoted to EPFRs have focused on their formation in different matrices, and more extensively, on their health effects. Limited studies have identified extensively the pollutants that are formed from EPFRs. Mechanistically, the formation of pollutants that are POPs or have parent structures classified as POPs is highly possible, which is limited only by the presence of precursors with the correct substituents. The potential in vivo formation of POPs in humans and other organisms is an additional exposure route and a concern. More investigation is needed to ascertain the type of pollutants that are formed from EPFRs. 
Knowledge about them will inform on the appropriate disposal methods and management controls to lessen our risk to them.

\section{Author Contributions}

EPV conceptualized, wrote, and edited the paper. JA, JL, and MM contributed to drafting and writing the paper.

\section{Funding}

EPV has been supported by the National Science Foundation EPSCoR RII-Track IV grant 1738337 and grant 1834638.

\section{Competing Interests}

The authors have declared that no competing interests exist.

\section{References}

1. Lomnicki S, Truong H, Vejerano E, Dellinger B. Copper oxide-based model of persistent free radical formation on combustion-derived particulate matter. Environ Sci Technol. 2008; 42: 4982-4988.

2. Vejerano E, Lomnicki S, Dellinger B. Lifetime of combustion-generated environmentally persistent free radicals on $\mathrm{Zn}(\mathrm{li}) \mathrm{O}$ and other transition metal oxides. J Environ Monit. 2012; 14: 2803-2806.

3. Zhu KC, Jia HZ, Sun YJ, Dai YC, Zhang C, Guo XT, et al. Long-term phototransformation of microplastics under simulated sunlight irradiation in aquatic environments: Roles of reactive oxygen species. Water Res. 2020; 173: 115564.

4. Cormier SA, Lomnicki S, Backes W, Dellinger B. Origin and health impacts of emissions of toxic by-products and fine particles from combustion and thermal treatment of hazardous wastes and materials. Environ Health Perspect. 2006; 114: 810-817.

5. Balakrishna S, Lomnicki S, McAvey KM, Cole RB, Dellinger B, Cormier SA. Environmentally persistent free radicals amplify ultrafine particle mediated cellular oxidative stress and cytotoxicity. Part Fibre Toxicol. 2009; 6: 11.

6. Xu Y, Yang LL, Wang XP, Zheng $M H$, Li C, Zhang $A Q$, et al. Risk evaluation of environmentally persistent free radicals in airborne particulate matter and influence of atmospheric factors. Ecotoxicol Environ Saf. 2020; 196: 110571.

7. Tong HJ, Lakey PS, Arangio AM, Socorro J, Shen FX, Lucas K, et al. Reactive oxygen species formed by secondary organic aerosols in water and surrogate lung fluid. Environ Sci Technol. 2018; 52: 11642-11651.

8. Khachatryan L, Vejerano E, Lomnicki S, Dellinger B. Environmentally persistent free radicals (EPFRs). 1. Generation of reactive oxygen species in aqueous solutions. Environ Sci Technol. 2011; 45: 8559-8566.

9. Ingram DJ, Tapley JG, Jackson R, Bond RL, Murnaghan AR. Paramagnetic resonance in carbonaceous solids. Nature. 1954; 174: 797-798. 
10. Vejerano EP, Rao GY, Khachatryan L, Cormier SA, Lomnicki S. Environmentally persistent free radicals: Insights on a new class of pollutants. Environ Sci Technol. 2018; 52: 2468-2481.

11. Valavanidis A, Iliopoulos N, Gotsis G, Fiotakis K. Persistent free radicals, heavy metals and PAHs generated in particulate soot emissions and residue ash from controlled combustion of common types of plastic. J Hazard Mater. 2008; 156: 277-284.

12. Tian LW, Koshland CP, Yano J, Yachandra VK, Yu IT, Lee SC, et al. Carbon-centered free radicals in particulate matter emissions from wood and coal combustion. Energy Fuels. 2009; 23: 2523-2526.

13. Jia HZ, Zhao S, Nulaji G, Tao KL, Wang F, Sharma VK, et al. Environmentally persistent Free radicals in soils of past coking sites: Distribution and stabilization. Environ Sci Technol. 2017; 51: 6000-6008.

14. dela Cruz AL, Gehling W, Lomnicki S, Cook R, Dellinger B. Detection of environmentally persistent free radicals at a superfund wood treating site. Environ Sci Technol. 2011; 45: 63566365.

15. Alderman SL, Farquar GR, Poliakoff ED, Dellinger B. An infrared and X-ray spectroscopic study of the reactions of 2-chlorophenol, 1,2-dichlorobenzene, and chlorobenzene with model CuO/Silica fly ash surfaces. Environ Sci Technol. 2005; 39: 7396-7401.

16. Farquar GR, Alderman SL, Poliakoff ED, Dellinger B. X-ray spectroscopic studies of the high temperature reduction of $\mathrm{Cu}(\mathrm{II}) \mathrm{O}$ by 2 -chlorophenol on a simulated fly ash surface. Environ Sci Technol. 2003; 37: 931-935.

17. Vejerano E, Lomnicki SM, Dellinger B. Formation and stabilization of combustion-generated, environmentally persistent radicals on $\mathrm{Ni}(\mathrm{II}) \mathrm{O}$ supported on a silica surface. Environ Sci Technol. 2012; 46: 9406-9411.

18. Thibodeaux CA, Poliakoff ED, Kizilkaya O, Patterson MC, DiTusa MF, Kurtz RL, et al. Probing environmentally significant surface radicals: Crystallographic and temperature dependent adsorption of phenol on ZnO. Chem Phys Lett. 2015; 638: 56-60.

19. Vejerano E, Lomnicki S, Dellinger B. Formation and stabilization of combustion-generated environmentally persistent free radicals on an $\mathrm{Fe}(\mathrm{III})_{2} \mathrm{O}_{3} /$ silica surface. Environ Sci Technol. 2011; 45: 589-594.

20. Spark KM, Swift RS. Effect of soil composition and dissolved organic matter on pesticide sorption. Sci Total Environ. 2002; 298: 147-161.

21. Liao SH, Pan B, Li H, Zhang D, Xing BS. Detecting free radicals in biochars and determining their ability to inhibit the germination and growth of corn, wheat and rice seedlings. Environ Sci Technol. 2014; 48: 8581-8587.

22. Odinga ES, Waigi MG, Gudda FO, Wang J, Yang B, Hu XJ, et al. Occurrence, formation, environmental fate and risks of environmentally persistent free radicals in biochars. Environ Int. 2020; 134: 105172.

23. Patterson MC, Keilbart ND, Kiruri LW, Thibodeaux CA, Lomnicki S, Kurtz RL, et al. EPFR formation from phenol adsorption on $\mathrm{Al}_{2} \mathrm{O}_{3}$ and $\mathrm{TiO}_{2}$ : EPR and EELS studies. Chem Phys. 2013; 422: 277-282.

24. Zhang CF, Zhang DD, Li ZL, Akatsuka T, Yang SY, Suzuki D, et al. Insoluble Fe-humic acid complex as a solid-phase electron mediator for microbial reductive dechlorination. Environ Sci Technol. 2014; 48: 6318-6325. 
25. Scott DT, McKnight DM, Blunt-Harris EL, Kolesar SE, Lovley DR. Quinone moieties act as electron acceptors in the reduction of humic substances by humics-reducing microorganisms. Environ Sci Technol. 1998; 32: 2984-2989.

26. Zhang CF, Katayama A. Humin as an electron mediator for microbial reductive dehalogenation. Environ Sci Technol. 2012; 46: 6575-6583.

27. Patterson MC, Thibodeaux CA, Kizilkaya O, Kurtz RL, Poliakoff ED, Sprunger PT. Electronic signatures of a model pollutant-particle system: Chemisorbed phenol on $\mathrm{TiO}_{2}(110)$. Langmuir. 2015; 31: 3869-3875.

28. Jia HZ, Zhao S, Shi YF, Zhu LY, Wang CY, Sharma VK. Transformation of polycyclic aromatic hydrocarbons and formation of environmentally persistent free radicals on modified montmorillonite: The role of surface metal ions and polycyclic aromatic hydrocarbon molecular properties. Environ Sci Technol. 2018; 52: 5725-5733.

29. Wu JZ, Liu YL, Zhang J, Zhou JZ, Liu ZX, Zhang, X, et al. A density functional theory calculation for revealing environmentally persistent free radicals generated on $\mathrm{PbO}$ particulate. Chemosphere. 2020; 255: 126910.

30. Jia HZ, Zhao S, Shi YF, Fan XY, Wang TC. Formation of environmentally persistent free radicals during the transformation of anthracene in different soils: Roles of soil characteristics and ambient conditions. J Hazard Mater. 2019; 362: 214-223.

31. Ruan XX, Liu YY, Wang GQ, Frost RL, Qian GG, Tsang DC. Transformation of functional groups and environmentally persistent free radicals in hydrothermal carbonisation of lignin. Bioresour Technol. 2018; 270: 223-229.

32. Chen QC, Wang MM, Sun HY, Wang X, Wang YQ, Li YG, et al. Enhanced health risks from exposure to environmentally persistent free radicals and the oxidative atress of $\mathrm{PM}_{2.5}$ from asian dust storms in Erenhot, Zhangbei and Jinan, China. Environ Int. 2018; 121: 260-268.

33. Arangio AM, Tong HJ, Socorro J, Pöschl U, Shiraiwa M. Quantification of environmentally persistent free radicals and reactive oxygen species in atmospheric aerosol particles. Atmos Chem Phys. 2016; 16: 13105-13119.

34. Gehling W, Dellinger B. Environmentally persistent free radicals and their lifetimes in $\mathrm{PM}_{2.5}$. Environ Sci Technol. 2013; 47: 8172-8178.

35. Shaltout AA, Boman J, Shehadeh ZF, Al-Malawi DR, Hemeda OM, Morsy MM. Spectroscopic investigation of $\mathrm{PM}_{2.5}$ collected at industrial, residential and traffic sites in Taif, Saudi Arabia. J Aerosol Sci. 2015; 79: 97-108.

36. Jankovic J, Jones W, Castranova V, Dalal N. Measurement of short-lived reactive species and long-lived free radicals in air samples from structural fires. Appl Occup Environ Hyg. 1993; 8: 650-654.

37. Watanabe A, McPhail DB, Maie N, Kawasaki S, Anderson HA, Cheshire MV. Electron spin resonance characteristics of humic acids from a wide range of soil types. Org Geochem. 2005; 36: 981-990.

38. Zhang HY, Sun YM, Chen DZ. O-H Bond dissociation energies of phenolic compounds are determined by field/inductive effect or resonance effect? A DFT study and its implication. Quant Struct Relatsh. 2001; 20: 148-152.

39. Dellinger B, Pryor WA, Cueto R, Squadrito GL, Hegde V, Deutsch WA. Role of free radicals in the toxicity of airborne fine particulate matter. Chem Res Toxicol. 2001; 14: 1371-1377. 
40. Maskos Z, Khachatryan L, Dellinger B. Role of the filters in the formation and stabilization of semiquinone radicals collected from cigarette smoke. Energy Fuels. 2013; 27: 5506-5512.

41. Nwosu UG. An investigation of environmentally persistent free radical (EPFR) formation in contaminated soils using surrogate-based model systems. Baton Rouge, Louisiana: Louisiana State University and Agricultural and Mechanical College; 2016.

42. Li H, Pan B, Liao SH, Zhang D, Xing BS. Formation of environmentally persistent free radicals as the mechanism for reduced catechol degradation on hematite-silica surface under UV irradiation. Environ Pollut. 2014; 188: 153-158.

43. Hasan F, Khachatryan L, Lomnicki S. Comparative studies of environmentally persistent free radicals on total particulate matter collected from electronic and tobacco cigarettes. Environ Sci Technol. 2020; 54: 5710-5718.

44. Hasan F, Khachatryan L, Lomnicki S. Comparative studies of environmentally persistent free radicals on total particulate matter collected from electronic and tobacco cigarettes. Environ Sci Technol. 2020; 54: 5710-5718.

45. Dellinger B, Loninicki S, Khachatryan L, Maskos Z, Hall RW, Adounkpe J, et al. Formation and stabilization of persistent free radicals. Proc Combust Inst. 2007; 31: 521-528.

46. Kiruri LW, Khachatryan L, Dellinger B, Lomnicki S. Effect of copper oxide concentration on the formation and persistency of environmentally persistent free radicals (EPFRs) in particulates. Environ Sci Technol. 2014; 48: 2212-2217.

47. Lee GI, Saravia J, You D, Shrestha B, Jaligama S, Hebert VY, et al. Exposure to combustion generated environmentally persistent free radicals enhances severity of influenza virus infection. Part Fibre Toxicol. 2014; 11: 57.

48. Truong H, Lomnicki S, Dellinger B. Potential for misidentification of environmentally persistent free radicals as molecular pollutants in particulate matter. Environ Sci Technol. 2010; 44: 1933-1939.

49. Jia HZ, Zhao S, Shi YF, Zhu KC, Gao P, Zhu LY. Mechanisms for light-driven evolution of environmentally persistent free radicals and photolytic degradation of PAHs on $\mathrm{Fe}$ (III)montmorillonite surface. J Hazard Mater. 2019; 362: 92-98.

50. Borrowman CK, Zhou SM, Burrow TE, Abbatt JP. Formation of environmentally persistent free radicals from the heterogeneous reaction of ozone and polycyclic aromatic compounds. Phys Chem Chem Phys. 2015; 18: 205-212.

51. Shi YF, Zhu KC, Dai YC, Zhang C, Jia HZ. Evolution and stabilization of environmentally persistent free radicals during the decomposition of lignin by laccase. Chemosphere. 2020; 248: 125931.

52. Zhu KC, Jia HZ, Zhao S, Xia TJ, Guo XT, Wang TC, Zhu LY. Formation of environmentally persistent free radicals on microplastics under light irradiation. Environ Sci Technol. 2019; 53: 8177-8186.

53. Ueno A, Shimizu S, Tamamura S, Okuyama H, Naganuma T, Kaneko K. Anaerobic decomposition of humic substances by clostridium from the deep subsurface. Sci Rep. 2016; 6: 1-9.

54. Trumbore SE. Potential responses of soil organic carbon to global environmental change. Proc Natl Acad Sci. 1997; 94: 8284-8291.

55. Lian F, Xing BS. Black carbon (biochar) in water/soil environments: Molecular structure, sorption, stability, and potential risk. Environ Sci Technol. 2017; 51: 13517-13532. 
56. Weber K, Quicker P. Properties of biochar. Fuel. 2018; 217: 240-261.

57. Zhu YH, Wei J, Liu YT, Liu XH, Li J, Zhang J. Assessing the effect on the generation of environmentally persistent free radicals in hydrothermal carbonization of sewage sludge. Sci Rep. 2019; 9: 17092.

58. Nwosu UG, Khachatryan L, Youm SG, Roy A, dela Cruz ALN, Nesterov EE, et al. Model system study of environmentally persistent free radicals formation in a semiconducting polymer modified copper clay system at ambient temperature. RSC Adv. 2016; 6: 43453-43462.

59. Zhao S, Zhang C, Ni Z, Zhu KC, Liu JB, Dai YC, et al. Optimized extraction of environmentally persistent free radicals from clays contaminated by polycyclic aromatic hydrocarbons. Environ Chem Lett. 2020; 18: 949-955.

60. Dellinger HB. PRES 1-dioxins, nanoparticles, environmentally persistent free radicals and combustion-generated air pollution. 236th ACS National Meeting; 2008 August 17-21; Philadelphia, U.S.Washington: Abstracts of Papers of the American Chemical Society.

61. Zhao S, Gao P, Miao D, Wu L, Qian YJ, Chen SP, et al. Formation and evolution of solventextracted and nonextractable environmentally persistent free radicals in fly ash of municipal solid waste incinerators. Environ Sci Technol. 2019; 53: 10120-10130.

62. dela Cruz AL, Cook RL, Lomnicki SM, Dellinger B. Effect of low temperature thermal treatment on soils contaminated with pentachlorophenol and environmentally persistent free radicals. Environ Sci Technol. 2012; 46: 5971-5978.

63. Mosonik BC, Kibet JK, Ngari SM, Nyamori VO. Environmentally persistent free radicals and particulate emissions from the thermal degradation of croton megalocarpus biodiesel. Environ Sci Pollut Res. 2018; 25: 24807-24817.

64. Jiang M, Bi DM, Huang FP, Wang JQ, Li BZ. Correlation between persistent free radicals of biochar and bio-oil yield at different pyrolysis temperatures. Bioresources. 2020; 15: 13841396.

65. Wang TJ, Chen T, Zhan MX, Guo Y, Li XD. Correlation of persistent free radicals, PCDD/Fs and metals in waste incineration fly ash. Huan Jing Ke Xue. 2016; 37: 1163-1170.

66. Potter PM, Dellinger B, Lomnicki SM. Contribution of aluminas and aluminosilicates to the formation of PCDD/Fs on fly ashes. Chemosphere. 2016; 144: 2421-2426.

67. Kiruri LW, Dellinger B, Lomnicki S. Tar balls from deep water horizon oil spill: Environmentally persistent free radicals (EPFR) formation during crude weathering. Environ Sci Technol. 2013; 47: 4220-4226.

68. Ruan XX, Sun YQ, Du WM, Tang YY, Liu Q, Zhang ZY, et al. Formation, characteristics, and applications of environmentally persistent free radicals in biochars: A review. Bioresour Technol. 2019; 281: 457-468.

69. Vejerano EP, Holder AL, Marr LC. Emissions of polycyclic aromatic hydrocarbons, polychlorinated dibenzo-p-dioxins, and dibenzofurans from incineration of nanomaterials. Environ Sci Technol. 2013; 47: 4866-4874.

70. Vance ME, Kuiken T, Vejerano EP, McGinnis SP, Hochella MF, Rejeski D, et al. Nanotechnology in the real world: Redeveloping the nanomaterial consumer products inventory. Beilstein J Nanotechnol. 2015; 6: 1769-1780.

71. Keller AA, Lazareva A. Predicted releases of engineered nanomaterials: From global to regional to local. Environ Sci Technol Lett. 2014; 1: 65-70. 
72. Vejerano EP, Rao GY, Khachatryan L, Cormier SA, Lomnicki SM. Environmentally persistent free radicals: Insights on a new class of pollutants. Environ Sci Technol. 2018; 52: 2468-2481.

73. Vejerano EW. Formation and stabilization of combustion-generated environmentally persistent free radicals on transition metal oxides supported on silica. Baton Rouge, Louisiana: Louisiana State University and Agricultural and Mechanical College; 2011.

74. Lomnicki, S.; Dellinger, B. A detailed mechanism of the surface-mediated formation of PCDD/F from the oxidation of 2-chlorophenol on a CuO/silica surface. J Phys Chem A. 2003; 107: 43874395.

75. Lomnicki S, Dellinger B. Formation of PCDD/F from the pyrolysis of 2-chlorophenol on the surface of dispersed copper oxide particles. Proc Combust Inst. 2002; 29: 2463-2468.

76. Truong H, Lomnicki S, Dellinger B. Mechanisms of molecular product and persistent radical formation from the pyrolysis of hydroquinone. Chemosphere. 2008; 71: 107-113.
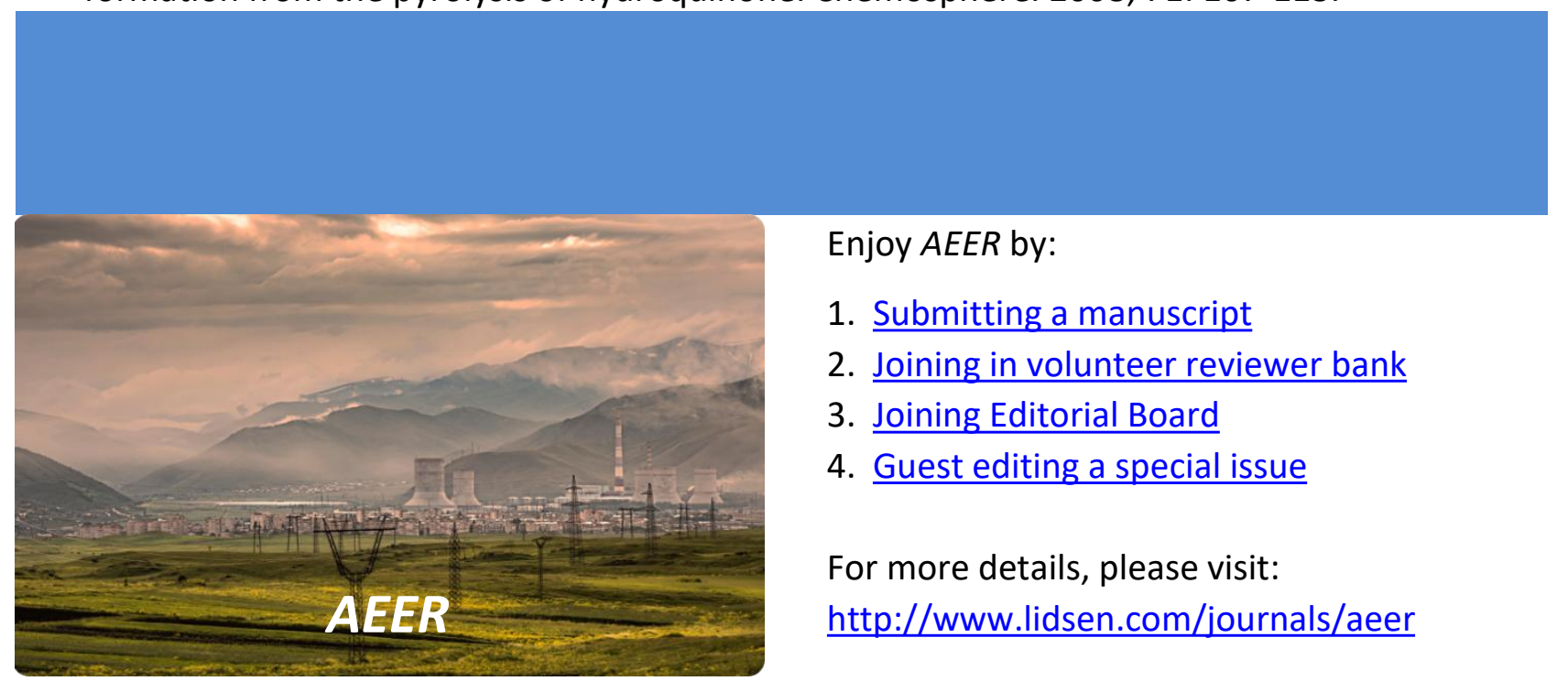

Enjoy $A E E R$ by:

1. Submitting a manuscript

2. Joining in volunteer reviewer bank

3. Joining Editorial Board

4. Guest editing a special issue

For more details, please visit:

http://www.lidsen.com/journals/aeer 